\title{
Improving the sustainability of food supply chains through circular economy practices - a qualitative mapping approach
}

\author{
Luciano Batista $^{1}$, Manoj Dora ${ }^{2}$, Jose Arturo Garza-Reyes ${ }^{3}$, Vikas Kumar ${ }^{4}$ \\ ${ }^{\text {I}}$ Aston Business School \\ Aston University, Birmingham, UK \\ ${ }^{2}$ Brunel Business School \\ Brunel University London, Uxbridge, UK \\ ${ }^{3}$ College of Business, Law and Social Sciences \\ The University of Derby, Derby, UK \\ ${ }^{4}$ Bristol Business School \\ University of the West of England, Bristol, UK
}

Keywords: food supply chain; food waste; circular economy; industrial ecosystems; qualitative mapping.

\section{Citation reference:}

Batista, Luciano; Dora, Manoj; Garza-Reyes, Jose A.; and Kumar, Vikas (2021). "Improving the sustainability of food supply chains through circular economy practices - a qualitative mapping approach", Management of Environmental Quality, Forthcoming, DOI (10.1108/MEQ-09-20200211). 
Improving the sustainability of food supply chains through circular economy practices - a qualitative mapping approach

\begin{tabular}{|r|l|}
\hline Journal: & Management of Environmental Quality \\
\hline Manuscript ID & MEQ-09-2020-0211.R3 \\
\hline Manuscript Type: & Research Paper \\
\hline Keywords: & $\begin{array}{l}\text { food supply chain, food waste, circular economy, industrial ecosystems, } \\
\text { qualitative mapping }\end{array}$ \\
\hline \multicolumn{2}{|l}{} \\
\hline
\end{tabular}

\section{SCHOLARONE ${ }^{\text {m }}$}

Manuscripts 


\begin{abstract}
Purpose

The purpose of this paper is to present a methodological approach to support qualitative analysis of waste flows in food supply chains. The methodological framework introduced allows the identification of circular food waste flows that can maximise the sustainability of food supply chains.

\section{Design/methodology/approach}

Following a qualitative approach, circular economy perspectives are combined with core industrial ecology concepts in the specification of a standardised analytical method to map food waste flows and industrial synergies across a supply chain.
\end{abstract}

\title{
Findings
}

The mapped waste flows and industrial linkages depict two time-related scenarios: 1. Current scenarios showing the status quo of existing food waste flows, and 2. Future scenarios pointing out circular flows along the supply chain. The future scenarios inform potential alternatives to take waste flows up the food waste hierarchy.

\section{Research limitations}

The qualitative approach do not allow generalisations of findings out of the scope of the study. The framework is intended for providing focused analysis, case by case. Future research involving mixedmethods where quantitative approaches complement the qualitative perspectives of the framework would expand the analytical perspective.

\section{Originality/Value}

The framework provides a relatively low cost and pragmatic method to identify alternatives to minimise landfill disposals and improve the sustainability of food supply chains. Its phased methodology and standardised outcomes serve as a referential basis to inform not only comparative analysis, but also policy making and strategic decisions aimed at transforming linear food supply chains into circular economy ecosystems.

Keywords: food supply chain; food waste; circular economy; industrial ecosystems; qualitative mapping.

\section{Introduction}

The environmental sustainability of food supply chains is a complex issue calling for sustainable practices that can be more realistically achievable by organisations operating in the food sector. The sector faces considerable challenges imposed by the limited availability of natural resources for food production on one hand, and the continuous increase of food consumption dictated by the rapid growth of populations on the other hand (Hertel, 2015). In this context, food waste represents a major problem that remains to be addressed more effectively (Read et al., 2020).

In order to improve its responsibility for the environment and society, the food sector needs to develop sustainable supply chains that minimise food waste by taking into account 
potential connections with a wider spectrum of organisations from diverse sectors operating in different geographical contexts (Ghosh et al., 2016).

Many managerial frameworks and approaches addressing this issue consider the extended scope of food supply chains (Steeneck and Sarin, 2017). Life cycle analysis (LCA) is one of the well-established analytical methods utilized in such approaches. Yet, extant literature reveals some criticism on its practical implementation due to the limited availability of customized quantitative data, involvement of expert know-how, and limited adoption by small firms due to the high costs involved (Lake et al., 2015; Scheepens et al., 2016).

This paper addresses these limitations by providing a pragmatic qualitative methodological approach to analysing food supply chain waste flows. The central contribution of the paper is to bring practices advocated by the circular economy into this context. To this end, the paper specifies a methodological framework of analysis that facilitates the identification of circular industrial linkages in food supply chains. Core principles of industrial ecology support the specification of a qualitative methodological framework that allows a standardised mapping of food waste flows, as well as the identification of more sustainable flows across a food supply chain. The framework is empirically tested in a study involving a short food supply chain in the UK.

In the next section, key food supply chain industries the research focused upon are identified and core conceptual aspects of food waste are introduced. This is followed by a section presenting the theoretical basis underlying the methodological framework developed in the study. The proposed methodology is an important outcome and contribution of the research, as it offers an original stepwise approach for the qualitative analysis of food waste flows. In the sequence, the findings of an empirical study where the framework was empirically tested are reported. The methodological and practical implications of the research are discussed in the subsequent section. The paper concludes by pointing out research limitations and identifying areas for future research.

\section{Industrial scope and theoretical basis}

This section defines the industrial scope of the food supply chain studied and the core theoretical perspectives the research takes into account.

\subsection{Relevant industries in food supply chains}

Key sectors in the food supply industry usually involve farming, manufacturing and retail operations. Although such supply chain scope may sound simple, the real context in which those industries operate is actually much more complex.

Deriving food waste scenarios and potential industrial synergies from supply networks is not a straightforward task. Previous studies have pointed out that approaches to analyse and mitigate the environmental impact of food supply chains without proper consideration of the interconnections between organisations and sectors in the chain are likely to fail (Cellura et al., 2012). To deal with the complexity of food supply chains, it is necessary to have the support of analytical methods that take into account the wider array of industries involved as well as their geographical configurations and potential cross-sectoral linkages across the supply chain.

This study provides a methodological framework that facilitates the mapping of food waste flows and identifies potential organisational synergies that minimise food waste in a 
food supply chain. The industrial scope considered in the research comprises companies representing key sectors of food production (farming and manufacturing) and commercialisation (retailing).

\subsection{Food waste and organisational synergies}

Food waste does not necessarily mean food that is not proper for consumption. In many food supply chains edible food is considered a disposable commodity, which is seen as 'waste' because it does not fulfil aesthetic requisites of presentation specified by retailers (Stuart, 2009).

In this study, food waste is considered as food which for any reason ends up in landfill before consumption (Amicarelli et al., 2020). This concept follows the definition of food waste provided by the Food and Agriculture Organization (FAO) of the United Nations, which defines food waste as any material intended for human consumption that at any point in the supply chain is discarded, degraded, lost or spoiled (FAO, 1981).

Finding alternatives to avoid food waste flows to landfill is a core concern of the circular economy, which advocates production systems that are restorative by purpose (Khan et al., 2020). The transition to a circular economy predicated on production systems which take into account opportunities for circular cycles of materials calls for more comprehensive approaches to identifying potential circularities linking diverse supply chain actors (Genovese et al., 2017; Nasir et al., 2017). This posits methodological challenges that are addressed in this study through the following research questions:

1. How can industrial configurations and related food waste flows in a food supply chain be captured without requiring too complex and costly methodological approaches?

2. How can circular industrial linkages to minimise food waste disposal in a supply chain be qualitatively mapped?

The answers to these questions depict distinct scenarios of food waste and industrial synergies one can potentially find across the major industrial activities in different stages of a food supply chain. In fact, a food supply chain presents different types of waste, as well as different waste flows and industrial synergy scenarios across the farming, manufacturing and retailing stages of the production value chain (Beske et al., 2014). The methodological framework developed in Section 3 provides a helpful and uncomplicated analytical method for the identification of the different scenarios of food waste flows across the supply chain. The framework also facilitates comparative analyses between distinct supply chain stages.

From an industrial ecology perspective, the industrial linkages the framework takes into account represent industrial synergies where the utilisation of waste resources can be maximised through the replacement of raw materials by food waste as inputs for further industrial processes (Maillé and Frayret, 2016). To identify potential organisational synergies across a food supply chain, information about material flows 'from' and 'into' organisations in the supply chain must be considered.

\subsection{Material flows in the circular economy}

Over the last decades, a growing body of literature has been establishing the philosophical and managerial paradigms of the circular economy, developing the theoretical and practical 
foundations that place sustainability and the prolonged use of resources as necessary capabilities of production systems (Lovins and Braungart, 2014). The maximisation of resources utilisation is a core tenet of the circular economy (Saroha et al., 2020). This principle is emphasised in the definition provided by Webster $(2015, \mathrm{p} .16)$, who defines circular economy as a sustainable economy "that is restorative by design, and which aims to keep products, components and materials at their highest utility and value, at all times".

In the circular economy, the high utilisation of resources by production systems involves industrial practices based on the circular flow of materials that can be used in multiple production instances (Geissdoerfer et al., 2017). These circular flows are based upon waste minimisation approaches such as reduce, redesign, reuse, repair, recycle and remanufacture (EM Foundation, 2014; Batista et al., 2019).

Business innovations to implement circular economy approaches can be achieved through the purposeful design of material recovery processes and related circular supply chains (Geissdoerfer et al., 2018). In essence this is grounded on the fundamental principle that a circular economy embraces the design of circular flows that enable the material recovery processes linking different organisations (Akturk et al., 2017). Such circular flows of materials are supported by supply chains that enable closed-loop returns to the focal company or forward open-loop flows linking organisations from diverse sectors (Batista et al., 2018).

The implementation of circular flows comprising closed- and open-loops increases the complexity and expands the scope of supply chain operations in the circular economy context. Following the call for more integrative approaches to designing sustainable supply chains (Bals and Tate, 2018), the design of circular supply chains should take into account more holistic perspectives integrating the different types of circular flows that maximise the recovery of materials. A wider perspective of industrial linkages is therefore considered in the methodological approach developed in this research.

\section{Methodological framework for qualitative food waste mapping}

This section introduces a methodological framework for a standardised qualitative analysis of food waste flows in a supply chain. The framework synthesises core concepts and approaches from previous studies and knowledge areas into a more practical and less complex analytical method. Specifically, the method follows a stepwise approach comprising three phases which lead to the generation of its main outcomes, as presented next.

\subsection{Phase 1 -Scope definition}

This phase specifies the unit of analysis and the key companies to be investigated. The unit of analysis refers to the specific food supply chain from which food waste flows and synergy scenarios are going to be identified. The key companies refer to the main organisations in each of the supply chain stages being analysed.

More specifically, Phase 1 involves the following steps, which are based on the initial steps of the classic LCA approach (Ardente et al., 2009):

a. Specification of the unit of analysis: Identification of the specific food supply chain to be investigated. In practice, this represents the main 'case' subject for study. 


\subsection{Phase 3 - Scenarios specification}

This phase involves the description of waste destination flows from each of the key companies in the supply chain. The scenarios have two time-related perspectives, one portraying the current waste destination flows and the other portraying future waste destination flows involving industrial linkages that can take place to either create or improve circular flows.

Ultimately, the future scenarios point out potential alternatives for supply chain transitions from linear to circular value chain ecosystems which divert material flows from landfill to other destinations where utilisation can take place. Such initiatives are based on a fundamental principle of the circular economy, which advocates the implementation of sustainable production and supply chain systems that seek to prolong the lifespan of products, by-products and waste (Lovins and Braungart, 2014). 
The initial step in this phase comprises the standard categorisation of waste flow scenarios with basis on the 'food recovery hierarchy' model specified the U.S. Environmental Protection Agency (EPA, 2014) shown in Figure 1. The model provides a helpful referential basis to classify, in a standardised way, the current and future waste flows identified in the analysis.

According to the model, the alternatives to divert waste flows from landfill are composting (e.g. creation of nutrient-rich soil amendment), industrial use (e.g. inputs into further production/commercialisation systems; recycling), feed animals (e.g. divert food scrap to animal use), feed people (e.g. divert food to feed people in need), and reduce waste generation.

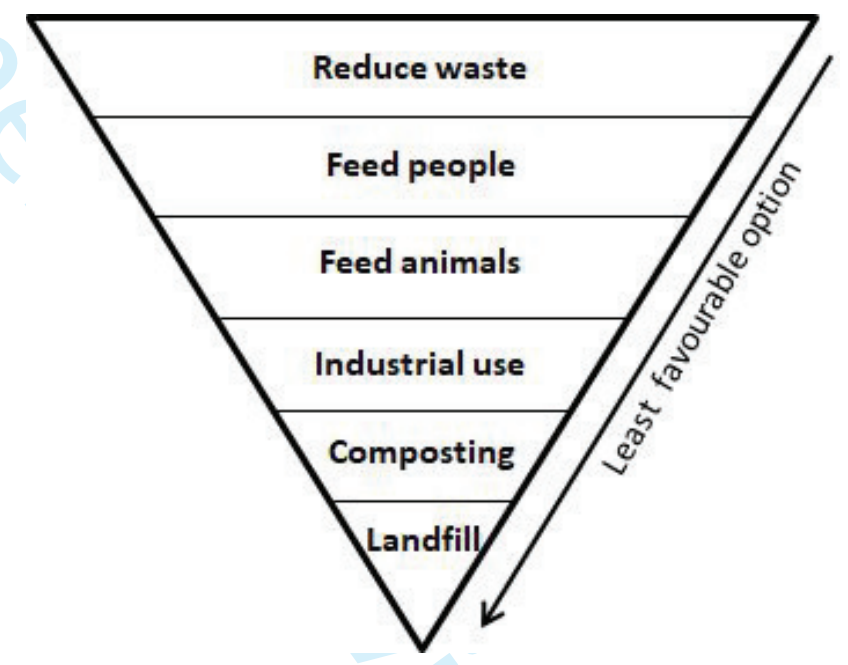

Figure 1. EPA Food recovery hierarchy model (adapted from EPA, 2014)

The EPA model also indicates an order of preference for processes that should be targeted as better alternatives for food waste flows to landfill. Accordingly, the future waste destination scenarios point out potential industrial connections that move current waste flows up the pyramid and, most importantly, out of landfill destinations. This is achieved through the identification of waste output streams from one organisation which can be used as input resources by other organisations inside or outside the supply chain being analysed. From a circular economy perspective, such scenario represents an optimisation of the circular flows in the ecosystem considered.

To complement the standardised characterisation of waste flow scenarios, the spatial scale typology of industrial symbiosis proposed by Chertow (2000) is applied. The spatial scale classification provides helpful insights regarding the geographical distances concerning waste flows. They point out distinct geographical configurations that demand different logistics operations for the material flows identified. From a spatial perspective, the general types of materials exchanged through industrial symbiosis connections are (Chertow, 2000; 2012):

- Type 1 - Through waste exchanges: Refers to materials exchange involving thirdparty brokers or dealers that create trading opportunities for waste and byproducts. 
- Type 2 - Within a facility, firm or organisation: Refers to exchanges that occur inside the scope of one organisation, without involving outside parties, e.g. between departments or productive areas of the same organisation.

- Type 3 -Among firms co-located in a defined industrial park: Refers to exchanges involving organisations located within a determined industrial park.

- Type 4-Among local firms that are not co-located: Refers to exchanges involving organisations that are not necessarily in the same industrial park; however, they are located in physical proximity within a specific geographic region.

- Type 5 - Among firms organised across a broader region: Refers to exchanges involving organisations that are not necessarily in geographical proximity; however, they can exchange materials by capitalising on existing logistics systems.

Figure 2 presents a summary of the methodological framework proposed, showing its three main phases and their expected outcomes.

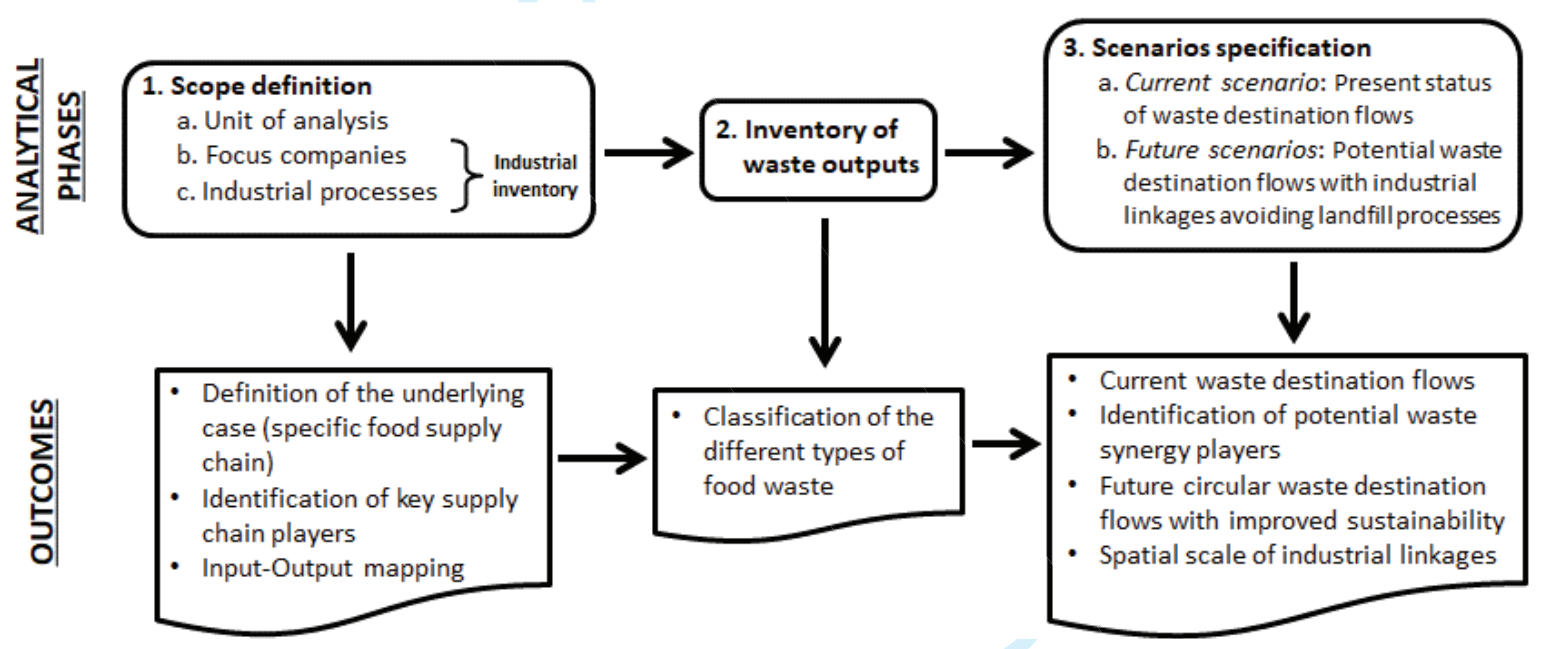

Figure 2. A methodological framework for the analysis of food waste flows and industrial synergies

The framework was applied in an empirical investigation to test its capacity to diagnose waste flow weaknesses and to identify improvement alternatives in food supply chains.

\subsection{Methodology of the empirical testing}

The framework above specified was applied in a qualitative research that mapped waste flows and industrial synergy scenarios in a food supply chain. The qualitative approach was chosen not to the detriment of quantitative approaches, but because the research was intentionally designed to develop a methodological framework of analysis that follows a qualitative mapping process.

The unit of analysis for the application of the framework was a particular supply chain of vegetables and derived products comprising organisations in the UK. The vegetables 
supply chain was targeted due to the increased challenges that products with fast perishability and short 'shelf life' bring to supply chains. Their production is usually associated with intensive use of water and re-packaging processes across the supply chain.

The specific supply chain represented the case context for the empirical test of the proposed framework. In conformity with qualitative research strategies (Bryman and Bell, 2015), the study involved semi-structured interviews, structured observations, as well as content analysis of documents and interview recordings. The interviews included open questions targeting specific information related to the three phases of the methodological framework being applied. The data analysis involved classification and categorisation of data by the research team against the categories defined in the analytical framework. More specifically, the process involved interpretative analysis where the researchers applied the standard classifications, categories, input/output flows and related types of industrial linkages specified in the methodological framework (Figure 2) to characterise the waste flow scenarios in each stage of the supply chain.

Reliability was achieved through peer debriefing technique, in which each researcher presented their analysis outcomes and conclusions to the other researchers in the team during the analysis process (Riege, 2003). This process fostered subsequent credibility of the qualitative interpretations and mapping of the case. To achieve validity, the study followed Silverman's (2020) recommendation to present the initial mapping outcomes back to the research participants, who had the opportunity to refine and confirm (validate) the mapping for their respective companies.

To reduce contextual complexity in the unit of analysis, three companies in the food supply chain considered for the research were targeted. Through theoretical purposive sampling (Yin, 2015), the companies were purposefully selected because they featured the core industrial stages of a food supply chain: farming, manufacturing and retailing. The organisations provided good convenience sampling opportunity (Eisenhardt and Graebner, 2007), meeting practical research strategy criteria. Altogether, the companies provided a suitable food supply chain context for analysis and empirical testing of the methodological framework developed in the research.

The interviews and validation meetings were conducted with the organisations' founders/CEOs, who had a comprehensive understanding of their respective suppliers, customers and key input/output flows in their organisations. The interviews, which were followed by site visits, lasted two hours on average and they were recorded with the consent of the participants.

\section{Research findings}

The framework of analysis allowed the generation of valuable insights whose practical application is facilitated by the standardised characterisation of food waste flows and identification of industrial linkages to improve the sustainability of the supply chain studied. The research findings are presented following the methodological phases of the analytical framework introduced in Section 3.

\subsection{Phase 1 - Scope definition}

The supply chain analysed involved three key agri-business players in the production and commercialisation of vegetables and derived products, namely: A food grower, a food 
manufacturer and a food retailer. These specific operations comprise typical production and service systems in food value chains, with system boundaries clearly defined at the level of farming, food processing and food retail respectively.

Table I provides the qualitative industrial inventory (Chertow, 2012) of the organisations in terms of generic input-output mapping of the main operations involved. The real names of the companies are not shown due to non-disclosure agreements.

Table I. Qualitative inventory of the systems in focus

\begin{tabular}{|c|c|c|}
\hline \multicolumn{3}{|c|}{ COMPANY A: FOOD GROWER - FARMING } \\
\hline Main input materials & Main operations & Main outputs \\
\hline $\begin{array}{l}\text { - Water } \\
\text { - Fertilizers } \\
\text { - Seeds } \\
\text { - Plastic sheets } \\
\text { - Packaging materials }\end{array}$ & $\begin{array}{l}\text { - Cultivation of broccoli, carrots, } \\
\text { runner beans and broad beans. } \\
\text { - Supplier of major UK } \\
\text { supermarkets and open markets in } \\
\text { the greater London region. }\end{array}$ & $\begin{array}{l}\text { - Washed, trimmed and packed } \\
\text { vegetables in small packs for } \\
\text { supermarkets. } \\
\text { - Large packs of vegetables for } \\
\text { wholesale in open markets. }\end{array}$ \\
\hline \multicolumn{3}{|c|}{ COMPANY B: FOOD PROCESSING - MANUFACTURING } \\
\hline Main inputs & Main operations & Main outputs \\
\hline $\begin{array}{l}\text { - Water } \\
\text { - Vegetables } \\
\text { - Herbs/spices } \\
\text { - Vegetable oil } \\
\text { - Packaging materials }\end{array}$ & $\begin{array}{l}\text { - Manufacturing of vegetable soups, } \\
\text { sauces and salad dressings. } \\
\text { - Supplier of major UK } \\
\text { supermarkets. }\end{array}$ & $\begin{array}{l}\text { - Fresh vegetable soups packed } \\
\text { in Tetra Pak packaging } \\
\text { - Sauces and salad dressings } \\
\text { packed in Tetra Pak packaging }\end{array}$ \\
\hline \multicolumn{3}{|c|}{ COMPANY C: FOOD SERVICE - RETAILING } \\
\hline Main inputs & Main operations & Main outputs \\
\hline $\begin{array}{l}\text { - General groceries, including } \\
\text { fresh fruits and vegetables. }\end{array}$ & $\begin{array}{l}\text { - Grocery retail } \\
\text { - Large chain of convenience shops } \\
\text { in the UK. }\end{array}$ & $\begin{array}{l}\text { - General groceries, including } \\
\text { fresh fruits and vegetables, sold } \\
\text { to end consumers. }\end{array}$ \\
\hline
\end{tabular}

The three companies identified in Table I are central players in the food supply chain studied. Their buyer-supplier relationships present the following industrial linkages:

- Company A (farmer) supplies Company B (manufacturer) with large packs of vegetables that will be used in the production of fresh soups, sauces and salad dressings.

- Company A also supplies Company C (retailer) with small packs of its own brand fresh vegetables that will be sold to end consumers.

- Company B supplies Company C with its own brand fresh vegetable soups, sauces and salad dressings.

\subsection{Phase 2 - Inventory of waste outputs}


In this phase, an inventory of waste materials was produced. The waste generated by each supply chain actor was identified and classified according to standard categories to facilitate qualitative analysis and comparisons of the main types of waste generated across the supply chain. The results are presented in Table II.

Table II. Inventory of waste outputs

\begin{tabular}{|c|c|c|}
\hline Company & Main waste material & Waste classification \\
\hline \multirow{5}{*}{$\mathbf{A}$} & $\begin{array}{l}\text { A1. Vegetables that do not meet customer specifications } \\
\text { (aesthetic requirements, labelling/packaging errors) }\end{array}$ & Nonconformity waste \\
\hline & A2. Vegetable cuttings from trimming processes & Processing waste \\
\hline & A3. Surplus vegetables (over supply quota) & Overproduction waste \\
\hline & A4. Plastic, paper and cardboards & Packaging waste \\
\hline & A5. Water from washing processes & Wastewater \\
\hline \multirow{5}{*}{ B } & $\begin{array}{l}\text { B1. Vegetable, herbs and spices } \\
\text { (spills, handling errors, machine failures) }\end{array}$ & Processing waste \\
\hline & B2. Vegetable oil used on cooking processes & Processing waste \\
\hline & $\begin{array}{l}\text { B3. Packed vegetable soups, sauces and salad dressings } \\
\text { (labelling errors, machine failures) }\end{array}$ & Processing waste \\
\hline & B4. Tetra Pak packaging & Packaging waste \\
\hline & B5. Water from washing and cooking processes & Wastewater \\
\hline \multirow{5}{*}{$\mathbf{C}$} & C1. Packed fresh vegetables (not sold by expiry date) & Overproduction waste \\
\hline & C2. Packed fresh vegetables (packaging damaged) & Processing waste \\
\hline & $\begin{array}{l}\text { C3. Packed vegetable soups, sauces and salad dressings } \\
\text { (not sold by expiry date) }\end{array}$ & Overproduction waste \\
\hline & $\begin{array}{l}\text { C4. Packed vegetable soups, sauces and salad dressings } \\
\text { (packaging damaged) }\end{array}$ & Processing waste \\
\hline & C5. Plastic, paper and cardboards & Packaging waste \\
\hline
\end{tabular}

Table II shows that 'processing waste' is the predominant type of food waste across the supply chain analysed and it is a major issue at manufacturing level (Company B). This can be explained by the higher degree of complexity involved in food manufacturing processes, which involves the application of different processes such as washing, cutting, cooking, mixing, packaging, etc. 'Overproduction waste' is an evident issue at farming and retail levels, suggesting difficulty of growers and retailers to match volume capacity with demand.

While 'packaging waste' is present across all stages in the supply chain, 'wastewater' is more localised at farming and manufacturing levels. Indeed, vegetable washing processes are more substantial in these two operational stages of the supply chain when compared to retailing. Finally, 'nonconformity waste' is an issue of more concern for growers, which in fact have more difficulty to produce on a regular basis vegetables with the aesthetic specifications required by retailers. 


\subsection{Phase 3 - Scenarios specification}

This phase involved the specification of destination flow scenarios for the main types of waste identified in the supply chain. The waste destination flows were analysed against the EPA model (Figure 1) and the spatial scale of the companies involved. The specification of current (actual) and future (circular) scenarios was structured in three sectoral contexts (farming, manufacturing and retailing), as discussed next.

\subsubsection{Current waste destination scenarios}

Table III provides a summary of the current waste destination flows identified in the case, including indication of the spatial scale typology related to the organisations involved.

Table III. Current waste destinations in the supply chain

\begin{tabular}{|c|c|c|c|}
\hline Company & Main waste material & $\begin{array}{l}\text { Waste } \\
\text { destination }\end{array}$ & $\begin{array}{l}\text { Spatial } \\
\text { scale }\end{array}$ \\
\hline \multirow{5}{*}{$\mathbf{A}$} & $\begin{array}{l}\text { A1. Vegetables that do not meet customer } \\
\text { specifications (aesthetic requirements, labelling / } \\
\text { packaging errors) }\end{array}$ & Industrial use & Type 5 \\
\hline & A2. Vegetable cuttings from trimming processes & Landfill & Type 1 \\
\hline & A3. Surplus vegetables (over supply quota) & Industrial use & Type 5 \\
\hline & A4. Plastic, paper and cardboards & Industrial use & Type 4 \\
\hline & A5. Water from washing processes & Industrial use & Type 2 \\
\hline \multirow{5}{*}{ B } & $\begin{array}{l}\text { B1. Vegetable, herbs and spices } \\
\text { (spills, handling errors, machine failures) }\end{array}$ & Landfill & Type 1 \\
\hline & B2. Vegetable oil used on cooking processes & Industrial use & Type 4 \\
\hline & $\begin{array}{l}\text { B3. Packed vegetable soups, sauces and salad } \\
\text { dressings (labelling errors, machine failures) }\end{array}$ & Feed people & Type 4 \\
\hline & B4. Tetra Pak packaging & Landfill & Type 1 \\
\hline & B5. Water from washing and cooking processes & Landfill & Type 2 \\
\hline \multirow{5}{*}{$\mathbf{C}$} & C1. Packed fresh vegetables (not sold by expiry date) & Industrial use & Type 4 \\
\hline & C2. Packed fresh vegetables (packaging damaged) & Feed animals & Type 4 \\
\hline & $\begin{array}{l}\text { C3. Packed vegetable soups, sauces and salad } \\
\text { dressings (not sold by expiry date) }\end{array}$ & Industrial use & Type 4 \\
\hline & $\begin{array}{l}\text { C4. Packed vegetable soups, sauces and salad } \\
\text { dressings (packaging damaged) }\end{array}$ & Feed animals & Type 4 \\
\hline & C5. Plastic, paper and cardboards & Industrial use & Type 4 \\
\hline
\end{tabular}

Most of the waste generated at the farming level (Company A) is used as input to other industrial processes. More specifically, 'nonconformity waste' (A1. vegetables that do not fulfil aesthetic requirements specified by retailers or present labelling/packaging errors after going through packaging processes) are currently sent to commercialisation in the wholesale market. This is the same destination of 'overproduction waste' (A3. surplus vegetable produce) which is not under exclusive supply contracts. 'Packaging waste' (A4) go to recycling organisations located within the farmer's region area (Type 4 spatial scale) and 'wastewater' (A5) is treated within the farm (Type 2 spatial scale) and used to reinforce its irrigation system. From a circular economy perspective, waste A2 (processing waste resulted 
from vegetable cutting/trimming processes) represents a major concern, as it currently goes to landfill. The grower disposes A2 for collection by waste collection services (Type 1 spatial scale).

At manufacturing level (Company B), waste B3 presents a social sustainability feature, as they are donated to NGO organisations running food banks and shelters in the region. The spatial linkage through which B3 flows is Type 4. However, the manufacturing company is not performing well in implementing sustainable flows for wastes B1, B4 and B5, which are currently destined to landfill. Used vegetable oil (waste B2) is currently taken by a recycling operations in the region which refines cooking oil into biofuel for power generation and heating.

The current waste flow scenario at retail level (Company C) presents good circularity levels, as there is no waste flow to landfill. Food not sold by the expiry date (wastes $\mathrm{C} 1$ and C3) is sent to local recycling operations for the production of compost. By its turn, food not sold due to packaging damage (wastes $\mathrm{C} 2$ and $\mathrm{C} 4$ ) is removed from the shelves and made available to local small farmers for animal feed purposes. Finally, packaging waste (C5) is sent to local recyclers. The waste flows originated from the retailer go to organisations located in geographic proximity within the same region. Therefore, the spatial scales of the food waste flows at retail level in the supply chain are categorised as Type 4 (Chertow, 2012).

\subsubsection{Future waste destination scenarios}

The current scenarios above mentioned pointed out areas in the food supply chain where linear flows of waste to landfill represent issues of concern. The specification of future waste destination scenarios allowed identification of alternative industrial linkages that can enable circular flows and improvements in the food recovery hierarchy. Figure 3 maps the areas in the supply chain where such improvements can occur. 


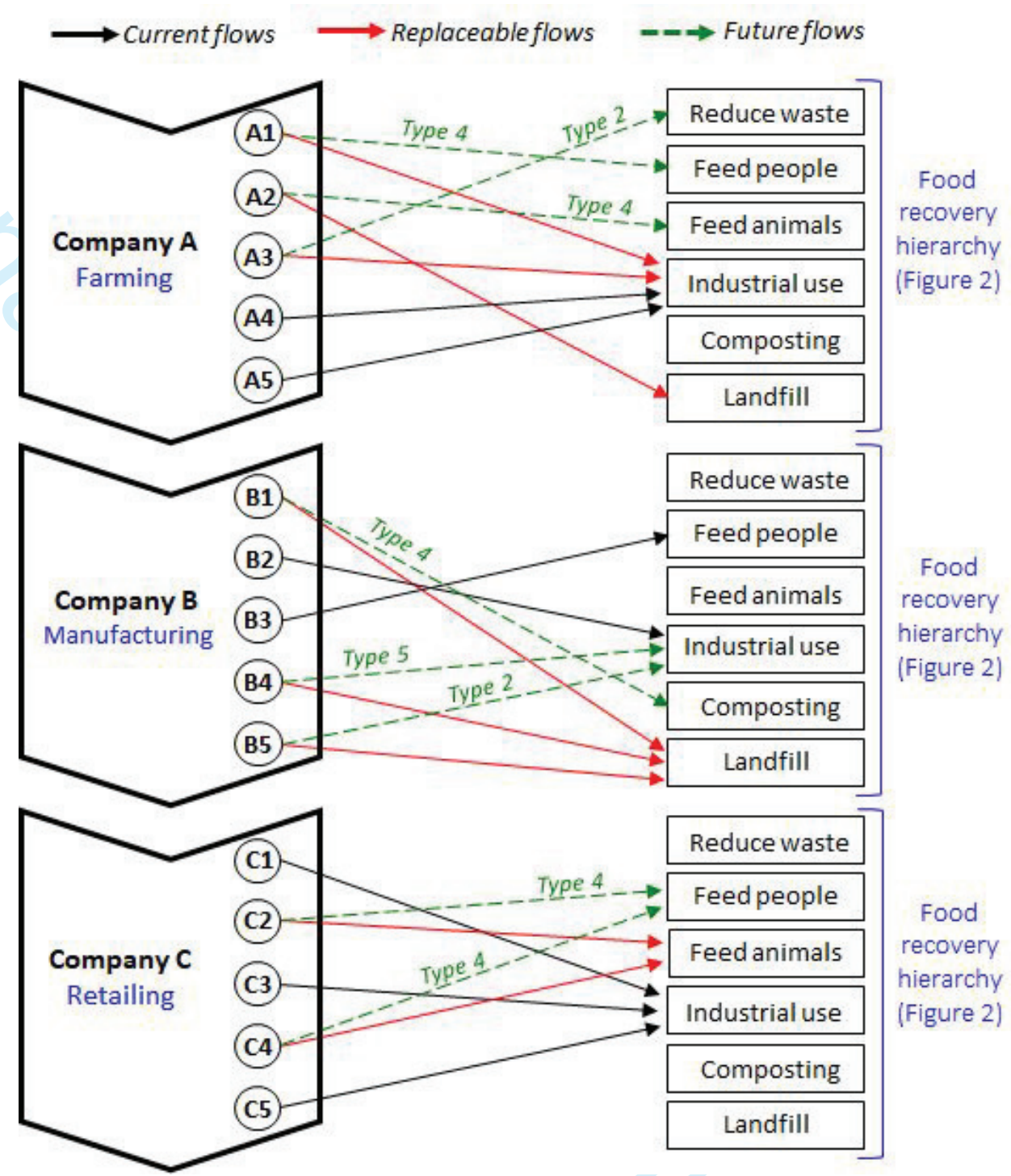

Figure 3. Potential food recovery improvements in the supply chain

Figure 3 offers valuable insights by putting together the fundamental concepts underpinning the sequential phases of the analytical framework. For instance, the circles represent the main waste materials generated by each company in the supply chain, as described in Table II. The arrows represent the waste destination flows for each waste material. The destinations are represented by the boxes on the right of the diagram. They correspond to the layers of the food recovery hierarchy model described in Figure 1. The arrows therefore indicate the hierarchy of waste destination flows. Moreover, each flow can be associated with a spatial scale linking the origin and destination of the material flows, as described in Table III. Such information provides important insights about the geographical dimensions involved in the flows, which have direct implications to the logistics systems involved. For example, Type 5 linkages might not be feasible if there are no logistics systems in place linking the organisations involved.

As shown in Figure 3, circularity improvements at farming level could be achieved through the implementation of alternative flows for A1, A2 and A3 types of waste. For instance, to improve social sustainability, part of the A1 waste could be destined to 'feed people' through NGOs running food banks or shelters. By their turn, vegetable cuttings and trimmings (waste A2) could be made available to local farmers for 'animal feed' purposes, 
instead of going to landfill. In addition, improvements in farming operations would allow reduction of overproduction waste (A3).

At food manufacturing level, waste flows to landfill (wastes B1, B4 and B5) should be replaced by more sustainable circular flows. This could be achieved by making B1 waste available to composting operations in the region through Type 4 spatial linkages. Wastewater (B5) could be treated and used in further internal processes. Tetra Pak packaging waste (B4) can be sent via Type 5 linkages to specific Tetra Pak recyclers which have the technology to recycle the more complex composition of Tetra Pak packages.

Finally, despite not having waste flows to landfill, improvements could be further achieved at retail level through shifting $\mathrm{C} 2$ and $\mathrm{C} 4$ waste flows up the food recovery hierarchy. For example, in many situations damaged packaging does not necessarily spoil the food content. In these cases, $\mathrm{C} 2$ and $\mathrm{C} 4$ waste could be destined to feed people by being made available to local NGOs running food banks or shelters.

\section{Discussion}

Overall, the research generated valuable methodological, practical and theoretical insights that complement the growing number of studies concerned with the sustainability of food supply chains. On the methodology side, it is possible to find in the literature a number of studies that apply qualitative methodology to investigate waste issues in food supply chains. An underlying issue concerning the myriad of qualitative studies in the area is the substantial variation of methods whose application is difficult to replicate, which creates fragmented perspectives that lack clear conceptualisation of a methodological framework that can standardise the analysis (Parfitt et al., 2010). This hinders replicability of research and the development of further qualitative studies that follow a coherent line of research enquiry involving the mapping of food waste and identification of industrial synergy scenarios.

In practical terms, the qualitative approach of the proposed framework provides a relatively low-cost and uncomplicated method to identify sustainable alternatives to minimise wasteful flows in food supply chains. For instance, it does not require investments to acquire sophisticated tools, software applications or expert skills. The framework was intentionally conceived to be pragmatically applied by organisations with limited computational resources and expertise. It therefore allows adoption by SMEs with limited financial and human resources. The framework's outcomes provide a useful referential basis to support decisionmaking processes to optimise food waste flows. For example, companies can use the 'future scenario' outcomes as a basis to develop strategic initiatives to improve their sustainability.

From a theoretical perspective, the framework is linked with relevant principles and approaches advocated by the circular economy. For instance, the specification of future waste destination scenarios identify potential industrial connections that move wasteful flows up in the food recovery hierarchy pyramid and, most importantly, out of landfill destinations. This is based upon a fundamental premise that underpins industrial transitions to the circular economy, which seeks to improve resource efficiency by systematically 'designing out' waste or avoiding material 'leakage to disposal' (EM Foundation, 2015; Webster, 2015).

Phase 1 (Scope definition) of the framework lends a systems thinking perspective to the analysis involved, requiring clear specification of the internal and external environments of the organisations operating in different stages of the supply chain. 'Systems thinking' is a fundamental theoretical perspective considered in circular economy approaches. In an 
industrial context, systems thinking considers businesses as entities that are part of a wider system of stakeholders as well as the environment in which they operate (Murray et al., 2017). For the circular economy, businesses should be considered in relation to their environmental context, rather than in isolation (Webster, 2015). A clear specification of the systems boundaries is a necessary step of the framework here developed, which facilitates the positioning of the companies studied as component parts of a wider food value chain ecosystem.

Phase 3 (Scenarios specification) takes into account the spatial scale typology proposed by Chertow (2000). Such categorisation brings insightful regional perspectives in the analysis, enabling wider perceptions of industrial network connections and potential synergies for materials exchange. This offers a valuable basis to support a holistic methodological approach to addressing food waste issues through potential solutions connecting organisations not only within in a specific supply chain, but also with organisations across diverse supply chains, linked to form wider circular economy ecosystems.

Phase 3 also involves the identification of waste flow scenarios in two time frames: current and future. The main objective of this process is the identification of circular flows which, in essence, represent circular economy alternatives for more sustainable supply chain ecosystems. Such perspective of analysis provides helpful insights to support policy making and the specification of sustainability strategies based on circular economy initiatives. For example, a current scenario mapping showing substantial landfill flows reveals a low circularity configuration (Batista et al., 2018). Companies can address this problem by performing a future scenario mapping, which aims to identify potential organisational linkages to create circular flows. The outcomes provide evidence to support the development of sustainability strategies through collaborations with potential companies identified in the mapping process.

\section{Conclusion}

This paper introduces the theoretical and methodological basis of a framework of analysis which brings circular economy perspectives into the core of the knowledge areas supporting analytical tools applied to minimise waste in food supply chains. In the paper, our main intention is to put forward a qualitative methodological framework of analysis which does not require costly resources and sophisticated skills to be applied.

The empirical application of the proposed framework yielded insightful outcomes, which unveil sustainability weaknesses and point out potential industrial synergies to address the identified weaknesses.

The framework however it is not exempt from limitations. One limitation is inherent of qualitative studies, from which research outcomes cannot be generalised to other settings that extrapolate the context of the empirical case. In order to reach maturity and reliability, the framework requires application in further research, including studies based on mixed method approaches were the qualitative methods of analysis are complemented by quantitative approaches that add generalisation power to the outcomes.

Future research involving quantitative approaches that complement the qualitative analysis of the framework here developed is recommended. For example, the different contexts of waste hierarchy processes, categories of food waste, and spatial scale of industrial 
linkages can all be numerically scored. Such quantitative approach can be applied in future research involving comparative analysis of sustainability performance indicators or simulation applications showing how future scenarios impact the sustainability of food supply chains.

\section{Acknowledgement}

The authors gratefully acknowledge the support provided the British Academy/Leverhulme Grant, Reference No: SG160072.

\section{References}

Akturk, M.S., Abbey, J.D. and Geismar, H.N. (2017), "Strategic design of multiple lifecycle products for remanufacturing operations", IISE Transactions, Vol. 49 No. 10, pp. 967-979.

Amicarelli, V., Bux, C. and Lagioia, G. (2020), "How to measure food loss and waste? A material flow analysis application", British Food Journal, Emerald Group Publishing Ltd.

Ardente, F., Cellura, M., Lo Brano, V. and Mistretta, M. (2009), "Life cycle assessment-driven selection of industrial ecology strategies", Integrated Environmental Assessment and Management, Vol. 6 No. 1, pp. 52-60.

Badurdeen, F., Iyengar, D., Goldsby, T.J., Metta, H., Gupta, S. and Jawahir, I.S. (2009), "Extending total life-cycle thinking to sustainable supply chain design", International Journal of Product Lifecycle Management, Vol. 4 No. 1/2/3, p. 49.

Bals, L. and Tate, W.L. (2018), "Sustainable Supply Chain Design in Social Businesses: Advancing the Theory of Supply Chain", Journal of Business Logistics, Vol. 39 No. 1, pp. 57-79.

Batista, L., Bourlakis, M., Smart, P. and Maull, R. (2018), "In search of a circular supply chain archetype - a content-analysis-based literature review", Production Planning \& Control, Vol. 29 No. 6, pp. 438-451.

Batista, L., Gong, Y., Pereira, S., Jia, F. and Bittar, A. (2019), "Circular Supply Chains in Emerging Economies - A comparative study of packaging recovery ecosystems in China and Brazil", International Journal of Production Research, DOI: 10.1080/00207543.2018.1558295.

Beske, P., Land, A. and Seuring, S. (2014), "Sustainable supply chain management practices and dynamic capabilities in the food industry: A critical analysis of the literature", International Journal of Production Economics, Vol. 152, pp. 131-143.

Bryman, A. and Bell, E. (2015), Business Research Methods, 4th Ed., Oxford University Press, Oxford.

Cellura, M., Ardente, F. and Longo, S. (2012), "From the LCA of food products to the environmental assessment of protected crops districts: a case-study in the south of Italy.", Journal of Environmental Management, Vol. 93 No. 1, pp. 194-208.

Chertow, M.R. (2000), "Industrial Symbiosis: Literature and Taxonomy", Annual Review of Energy and the Environment, Annual Reviews 4139 El Camino Way, P.O. Box 10139, Palo Alto, CA 94303-0139, USA, Vol. 25 No. 1, pp. 313-337.

Chertow, M.R. (2012), "Industrial symbiosis", The Encyclopedia of Earth, available at: http://www.eoearth.org/view/article/153824/ (accessed 17 October 2018).

Darlington, R., Staikos, T. and Rahimifard, S. (2009), "Analytical methods for waste minimisation in the convenience food industry.”, Waste Management, Vol. 29 No. 4, pp. 1274-81.

Eisenhardt, K.M. and Graebner, M.E. (2007), "Theory Building From Cases: Opportunities And Challenges", Academy of Management Journal, Vol. 50 No. 1, pp. 25-32.

EM Foundation. (2014), Towards the Circular Economy - Volume 3: Accelerating the Scale-up across Global Supply Chains, Ellen MacArthur Foundation, Cowes, Isle of Wight.

EM Foundation. (2015), Towards a Circular Economy: Business Rationale for an Accelerated Transition, Greener Management International, Ellen MacArthur Foundation, Cowes, Isle of 
Wight.

EPA. (2014), “Reducing Wasted Food \& Packaging”, U.S. Environmental Protection Agency, EPA909-K-14-002.

FAO. (1981), Food Loss Prevention in Perishable Crops, Rome, available at: http:/www.fao.org/docrep/s8620e/s8620e00.htm\#Contents.

Geissdoerfer, M., Morioka, S.N., de Carvalho, M.M. and Evans, S. (2018), "Business models and supply chains for the circular economy”, Journal of Cleaner Production, Vol. 190, pp. 712-721.

Geissdoerfer, M., Savaget, P., Bocken, N.M.P. and Hultink, E.J. (2017), “The Circular Economy - A new sustainability paradigm?”, Journal of Cleaner Production, Vol. 143, pp. 757-768.

Genovese, A., Acquaye, A.A., Figueroa, A. and Koh, S.C.L. (2017), "Sustainable supply chain management and the transition towards a circular economy: Evidence and some applications", Omega, Vol. 66, pp. 344-357.

Ghosh, P.R., Fawcett, D., Sharma, S.B. and Poinern, G.E.J. (2016), "Progress towards Sustainable Utilisation and Management of Food Wastes in the Global Economy", International Journal of Food Science, Vol. 2016, pp. 1-22.

Heidrich, O. and Tiwary, A. (2013), “Environmental appraisal of green production systems: Challenges faced by small companies using life cycle assessment”, International Journal of Production Research, Routledge, Vol. 51 No. 19, pp. 5884-5896.

Hertel, T.W. (2015), “The challenges of sustainably feeding a growing planet”, Food Security, Vol. 7 No. 2, pp. 185-198.

Khan, S., Maqbool, A., Haleem, A. and Khan, M.I. (2020), “Analyzing critical success factors for a successful transition towards circular economy through DANP approach", Management of Environmental Quality: An International Journal, Vol. 31 No. 3, pp. 505-529.

Kuik, S.S., Nagalingam, S. V. and Amer, Y. (2011), "Sustainable supply chain for collaborative manufacturing", edited by Choy, K.L. Journal of Manufacturing Technology Management, Vol. 22 No. 8, pp. 984-1001.

Lake, A., Acquaye, A., Genovese, A., Kumar, N. and Koh, S.C.L. (2015), “An application of hybrid life cycle assessment as a decision support framework for green supply chains", International Journal of Production Research, Vol. 53 No. 21, pp. 6495-6521.

Lovins, A. and Braungart, M. (2014), A New Dynamic - Effective Business in a Circular Economy, 2nd ed., Ellen MacArthur Foundation Publishing, Cowes, Isle of Wight.

Maillé, M. and Frayret, J.-M. (2016), “Industrial Waste Reuse and By-product Synergy Optimization”, Journal of Industrial Ecology, Vol. 20 No. 6, pp. 1284-1294.

Murray, A., Skene, K. and Haynes, K. (2017), "The Circular Economy: An Interdisciplinary Exploration of the Concept and Application in a Global Context", Journal of Business Ethics, Vol. 140 No. 3, pp. 369-380.

Nasir, M.H.A., Genovese, A., Acquaye, A.A., Koh, S.C.L. and Yamoah, F. (2017), “Comparing linear and circular supply chains: A case study from the construction industry", International Journal of Production Economics, Vol. 183, pp. 443-457.

Pandey, R.U., Surjan, A. and Kapshe, M. (2018), "Exploring linkages between sustainable consumption and prevailing green practices in reuse and recycling of household waste: Case of Bhopal city in India", Journal of Cleaner Production, Vol. 173, pp 49-59.

Parfitt, J., Barthel, M. and Macnaughton, S. (2010), "Food waste within food supply chains: Quantification and potential for change to 2050.”, Philosophical Transactions of the Royal Society of London, Vol. 365 No. 1554, pp. 3065-3081.

Read, Q.D., Brown, S., Cuéllar, A.D., Finn, S.M., Gephart, J.A., Marston, L.T., Meyer, E., et al. (2020), "Assessing the environmental impacts of halving food loss and waste along the food supply chain", Science of the Total Environment, Vol. 712, p. 136255.

Riege, A.M. (2003), "Validity and reliability tests in case study research: A literature review with 'hands-on' applications for each research phase", Qualitative Market Research: An International Journal, Vol. 6 No. 2, pp. 75-86. 
Saroha, M., Garg, D. and Luthra, S. (2020), "Pressures in implementation of circular supply chain management for sustainability: An analysis from Indian industries perspective", Management of Environmental Quality: An International Journal, Vol. 31 No. 5, pp. 1091-1110.

Scheepens, A.E., Vogtlander, J.G. and Brezet, J.C. (2016), “Two life cycle assessment (LCA) based methods to analyse and design complex (regional) circular economy systems. Case: Making water tourism more sustainable", Journal of Cleaner Production, Vol. 114, pp. 257-268.

Silverman, D. (2020), Interpreting Qualitative Data, 6th Edition, Sage Publications Ltd, London.

Steeneck, D.W. and Sarin, S.C. (2017), "Determining end-of-life policy for recoverable products", International Journal of Production Research, Vol. 55 No. 19, pp. 5782-5800.

Stuart, T. (2009), Waste: Uncovering the Global Food Scandal, W. W. Norton \& Company, New York.

Webster, K. (2015), The Circular Economy - a Wealth of Flows, Ellen MacArthur Foundation Publishing, Cowes, Isle of Wight.

Yin, R. (2015), Qualitative Research from Start to Finish, Second Edi., The Guilford Press, New York. 